\title{
Cuidados de Enfermagem em Tempos de Pandemia: Uma Realidade Hospitalar
}

\section{Nursing Care in Times of Pandemic: A Hospital Reality}

Sara Torcato Parreira ${ }^{1}$, Glória Ribeiro², José Coelho ${ }^{3}$, Luzia Borges ${ }^{4}$

\section{RESUMO}

A pandemia de COVID-19 trouxe novos desafios ao sistema de saúde em Portugal e, consequentemente, aos profissionais da área, nos quais se destacam as equipas de enfermagem pelo seu papel na prestação direta de cuidados e na organização dos serviços. Este artigo descreve as alterações realizadas na CUF Infante Santo Hospital para responder à pandemia e o papel das equipas de enfermagem neste contexto, sobretudo a nível de internamento hospitalar, serviço de ambulatório, cuidados domiciliários e serviço de Oncologia.

As intervenções e cuidados de enfermagem foram fulcrais na organização e bom desempenho do hospital face à pandemia. Houve, inclusive, uma melhoria nos sistemas de comunicação e articulação com outros serviços e equipas e da consciencialização da importância das medidas de controlo de infeção, o que reforça a necessidade de manutenção e investimento nalgumas destas intervenções e medidas no futuro.

PALAVRAS-CHAVE: COVID-19; Cuidados de Enfermagem; Infeções por Coronavírus

1. Enfermeira Perita, Hospital de Dia de Oncologia, CUF Infante Santo Hospital, Lisboa, Portugal. 2. Enfermeira Gestora, Consultas Externas, CUF Infante Santo Hospital, Lisboa, Portugal. 3. Enfermeiro Diretor CUF Infante Santo Hospital, Lisboa, Portugal. 4. Enfermeira Perita, GCL PPCIRA, CUF Infante Santo Hospital, Lisboa, Portugal.

Recebido/Received: 05/06/2020 - Aceite/Accepted: 14/06/2020 - Publicado/Published: 30/06/2020

(C) Autor (es) (ou seu (s) empregador (es)) 2020. Reutilização permitida de acordo com CC BY-NC. Nenhuma reutilização comercial. (c) Author(s) (or their employer(s)) 2020. Re-use permitted under CC BY-NC. No commercial re-use. 


\section{ABSTRACT}

COVID-19 pandemic became a challenge for the health system in Portugal and for health professionals. Nurses had an enhanced role, due to direct patient care and units management.

This article describes how CUF Infante Santo Hospital managed care during the pandemic and nurses' role, mainly in the wards, ambulatory setting, home care and oncology department.

Nursing interventions and care were essential for the good performance of the hospital in times of pandemic. Communication and connection with other units and teams were improved, as well as infection control. This reinforce the need to maintain and invest in some of these interventions in the future.

KEYWORDS: Coronavirus Infections; COVID-19; Nursing Care

\section{ENFERMAGEM EM TEMPOS DE PANDEMIA}

A 31 de dezembro de 2019 foi reportada à Organização Mundial da Saúde (OMS) uma pneumonia de causa desconhecida em Wuhan, na China. ${ }^{1}$ A doença - COVID-19 - causada pelo novo coronavírus (SARS-CoV-2), é transmitida por gotículas que podem contaminar pessoas numa curta distância ou objetos e superfícies. ${ }^{2}$ A 11 de março de 2020, a Organização Mundial da Saúde declarou a COVID-19 como pandemia.

Muitas incertezas advieram com a chegada do vírus no início de março de 2020 a Portugal e o medo era uma constante perante o desconhecido. Pouco a pouco foi-se demonstrando que a transmissão também ocorria de pessoa-a-pessoa, através de gotículas, mas não era claro o seu mecanismo; sabia-se da possibilidade de contaminação por contacto, mas não se sabia o tempo da sobrevivência do vírus. $\bigcirc$ facto do reservatório e da história natural da doença continuar em investigação, aliado à inexistência de tratamento conveniente, manteve o nível de preocupação alto.

As estruturas governamentais, comunitárias, as empresas e hospitais tiveram de elaborar os seus planos de contingência e a CUF Infante Santo não foi exceção, tendo sido também designado como um dos hospitais da zona de Lisboa para o atendimento a pessoas com sintomas suspeitos ou diagnóstico de COVID-19. Neste sentido, estabeleceram-se, desde cedo, objetivos e prioridades no modo de funcionamento da instituição e dos serviços.

Tornou-se imperativo reformular a forma como vivíamos o hospital. Na verdade, seria criar um novo hospital dentro de um hospital com mais de 70 anos, que fosse capaz de proteger profissionais e doentes, o que se revelou um derradeiro desafio. Implicou horas sobre ho- ras, noites com muitas inquietações, reuniões sem fim na tentativa de estruturar convenientemente um "hospital COVID". Para delinear as ações seguiu-se a estratégia multimodal das precauções básicas de controlo de infeção (PBCl):

- Colocação do doente COVID-19 e que circuito faria;

- Utilização de equipamentos de proteção individual (EPIs): que EPI e qual a melhor sequência de colocar e remover;

- Reforço da higiene das mãos e de solução antisséptica de base alcoólica (SABA);

- Reforço da etiqueta respiratória em colaboradores, mas também educação dos doentes;

- Criação de novos planos de higiene ambiental com a Gestão Hoteleira: como descontaminar equipamento clínico durante a pandemia; como manusear a roupa de forma segura; como recolher de forma segura os resíduos hospitalares e como agir perante a exposição ao agente microbiano no local de trabalho.

Todas estas questões careciam de resposta em tempo recorde. Nunca trabalhar em equipa, de forma multidisciplinar, foi tão importante. $\mathrm{O}$ envolvimento dos administradores, desde o primeiro momento, das direções, de todas as áreas clínicas e não clínicas que compõem o hospital, nomeadamente gestores de unidade, manutenção, comunicação, marketing, gestão hoteleira, logística, farmácia, entre outros, permitiram um alinhamento estratégico jamais visto noutro contexto, como se de uma orquestra se tratasse, mostrando a flexibilidade necessária para a adaptação às várias mudanças, consoante o nível de conhecimento que se obtinha do contexto epidemiológico do país e das investigações que se iam revelando como sendo evidência.

Esta profunda metamorfose, quer na estrutura física, quer em termos de organização de equipas foi sempre 
controlada pelo Grupo de Controlo Local do Programa de Prevenção e Controlo de Infeções e Resistência aos Antimicrobianos (GCL-PPCIRA), que se revelou como o maestro desta orquestra hospitalar. Mas também as enfermeiras responsáveis da área da Gestão do Risco e do Sistema Nacional de Avaliação em Saúde (SINAS) foram aliadas imprescindíveis, e o braço direito, para a implementação das medidas e alterações no hospital.

Transmitir segurança aos profissionais era uma obrigação, mas simultaneamente, uma prioridade da instituição e do GCL-PPCIRA. Houve grande dificuldade, durante este período conturbado, em obter EPIs com a qualidade exigida e na quantidade necessária. Foi um desafio diário, mas superado, ao ser possível, de forma estruturada, organizar equipas e processos e cuidar dos profissionais que estavam na linha da frente. $\bigcirc$ fornecimento de fardas higienizadas, o permanente acompanhamento das equipas, saber das suas dificuldades, dos constrangimentos, ajudar a equipar e desequipar, esclarecer dúvidas, apenas foi possível pela colaboração dos Elos de Enfermagem do GCL-PPCIRA, que tiveram um papel preponderante durante esta crise. Outra intervenção de valor foi a disponibilização de local para poderem pernoitar os profissionais que queriam evitar ir a casa, com receio de contaminarem os seus familiares. A entrega de produtos de higiene e hidratação e de bens alimentares foi outras das medidas de cuidados para com os profissionais e que os fez sentirem-se valorizados.

A formação nunca se revelou tão fundamental, com a intervenção dos elos de enfermagem do PPCIRA. Estiveram disponíveis, presencialmente, nos 7 dias da semana realizando formações a todos os profissionais da instituição e esclarecendo dúvidas. A par destas formações foi disponibilizado diariamente um Boletim Informativo para colaboradores, que reforçava a informação disponibilizada pela equipa do PPCIRA e acrescentava novas orientações locais e/ou diretrizes divulgadas pela Direção Geral da Saúde (DGS). A comunicação e informação, via digital ou presencial pelos elos locais de enfermagem ou elementos das equipas de gestão, revelou-se de extrema importância na gestão do dia-a- dia de cuidados, pois, tal como referido em fevereiro no editorial da Lancet "There may be no way to prevent a COVID-19 pandemic in this globalised time, but verified information is the most effective prevention against the disease of panic". ${ }^{3}$ De facto, todas as alterações e novas orientações tinham de chegar em tempo útil às equipas. Aqui, pontos de situação diários, com equipas multidisciplinares, recorrendo às várias plataformas de videoconferência permitiram esta celeridade. Tratando-se de uma maratona, mas onde a adrenalina e necessidades imprimiam um modo sprint, foi importante a gestão das equipas e energia e são vários artigos com a mesma visão. ${ }^{4}$ A delegação de funções, assim como a rotatividade das equipas, foram duas das iniciativas praticadas nesta dinâmica. Interessante verificar que, do outro lado do Atlântico, como em Seattle, foram sentidas e identificadas exatamente as mesmas necessidades e prioridades no que concerne à importância da comunicação, delegação, foco na equipa e sustentabilidade na organização e atividades dos serviços. ${ }^{5}$

Numa visão mais alargada, tornar a instituição num "hospital COVID" contou com a forte convicção e sentido de missão por parte dos profissionais de saúde, exemplar por parte dos enfermeiros, auxiliares e médicos e por parte da equipa de limpeza que se superou durante esta crise. Com forte envolvimento das equipas de gestão de enfermagem, com grande foco no planeamento de recursos materiais, profissionais e seguindo as mais recentes orientações clínicas foi possível preparar todo um hospital e suas equipas para responder às necessidades de saúde de uma cidade.

De um modo mais específico, houve alterações no funcionamento de vários serviços do hospital e na prestação de cuidados de enfermagem.

No Internamento, houve um tempo de preparação, sobretudo para organização e arrumações, desde retirar dos quartos todo o mobiliário possível, proteger comandos, computadores e seus teclados, esvaziar prateleiras de medicação, de consumíveis, preparar carros com EPIs para usar, marcar o chão com as fitas indicativas de risco, vermelhas (quarto), amarelas (corredor) e verde na zona de transfer preparada para deixar o serviço.

A comunicação de que o primeiro doente COVID-19 estava para ser internado deixou toda a equipa tensa. Existiam cartazes indicativos dos EPIs a usar na porta de cada quarto e na entrada e saída do serviço, como deviam ser colocados e retirados (Fig. 1), mas ter de realizar este procedimento pela primeira vez, para um doente confirmado, gerou ansiedade e medo de falhar e ser contaminado. A insegurança e receio de ficar infetado e transmitir aos familiares próximos era grande. As notícias e redes sociais tinham um grande impacto, já que mostravam dia-a-dia a dimensão da pandemia, a falta de resposta dos sistemas de saúde dos outros países e o número de vítimas mortais, nomeadamente nos profissionais de saúde, o que contribuía para a escalada no medo.

Tudo era novo, uma doença nova, um hospital "novo" com novos circuitos, procedimentos novos, cuidados de 
rotina que se alteraram devido ao risco que acarretavam. A atuação em caso de paragem cardiorrespiratória era uma delas. De repente, a formatação da assistência treinada durante anos não podia ser realizada. Numa situação de paragem era preciso uns segundos para pensar antes de agir. $\bigcirc$ paradigma tinha mudado. A segurança do enfermeiro estava em primeiro lugar. Começava quando entrava no hospital, onde tinha de ter a preocupação em retirar todos os adornos, em trocar calçado, em realizar a higiene das mãos e, no fim do turno, a necessidade de tomar duche, apesar de todos os cuidados.

Durante o turno, era necessário estar atento a tudo. Planear os cuidados ao pormenor, evitar entradas e exposição desnecessária, ter presente as técnicas que não podiam ser realizadas. Usar durante horas os EPIs, com o desconforto inerente e inevitável. Foi impossível não sair exausto deste ambiente de hiperestimulação com marcas, muitas delas invisíveis.

O impacto na prestação de cuidados foi notório. Houve uma menor diversidade de profissionais e o número de vezes que se entrava nos quartos de internamento também reduziu. Só estava quem precisava mesmo de estar, quando fosse necessário. $\mathrm{O}$ enfermeiro era o motor e executante da maioria dos cuidados, desde o banho, à administração da medicação até à realização de colheitas sanguíneas e promotor da comunicação entre doente e médico ou entre doente e família.

Como consequência, houve uma grande necessidade de investir na promoção do autocuidado, algo que é core das intervenções de enfermagem. Por outro lado, o isolamento do doente, sem direito a visitas, fazia com que o profissional de saúde fosse a sua companhia, apesar de existir a possibilidade de contacto com os familiares via internet.

A equipa de enfermagem continuou a demonstrar grande empatia e humanidade para ser sensível à necessidade do outro. $O$ enfermeiro continuou a preparar a alta e a fazer chegar informação aos familiares ou cuidadores com o mesmo empenho. Melhorou-se, até, a articulação com outros profissionais e serviços, dentro e fora da rede CUF.

Pouco a pouco os profissionais tornaram-se mais confiantes, o que trouxe mais elementos da equipa multidisciplinar para o chamado "Covidário". Colocar e retirar EPIs era rotineiro. Estava cimentado. Os procedimentos emanados pela DGS vinham suportar o que já estava instituído, criando maior confiança.

Na Oncologia, por se tratar de um grupo de doentes de risco, o serviço organizou-se de forma a segregar o cir- cuito destes doentes, minimizar o número de vindas ao hospital (utilizando, por exemplo, teleconsulta) e monitorizar, com maior regularidade, os sinais e sintomas. A equipa de enfermagem redefiniu a sua estrutura, de forma a responder às novas valências e a assegurar a segurança e prestação de cuidados aos doentes oncológicos por enfermeiros devidamente treinados e com competências específicas, de acordo com as recomendações da Sociedade de Enfermagem Oncológica. ${ }^{6}$

Neste sentido, para minimizar o risco de potencial infeção pelo novo coronavírus, e por se tratar de um "hospital COVID", foi necessário estabelecer um circuito próprio para os doentes oncológicos, devidamente segregado das restantes áreas hospitalares. Vários foram os testemunhos de doentes a comprovar que esta alteração Ihes transmitia segurança e confiança no hospital, na equipa e nos cuidados. À entrada, um enfermeiro de oncologia procedia ao rastreio da sintomatologia e epidemiologia associadas ao novo coronavírus. A colheita de análises passou, também, a ser realizada por este profissional, limitando a deslocação do doente ao serviço de Patologia Clínica e a sua circulação no hospital. Os exames complementares necessários eram realizados noutras unidades CUF, o que melhorou a articulação com as mesmas. Em Hospital de Dia houve um alargamento do horário de funcionamento do serviço, de forma a permitir uma menor ocupação da sala de tratamentos. E, seguindo as indicações da norma 9/2020 da DGS, 7 todos os doentes sob quimioterapia sistémica, começaram a ser testados laboratorialmente para SARS-CoV-2 antes da realização do tratamento e, também, em situações que implicassem radioterapia ou intervenção cirúrgica.

De extrema importância foi a disponibilização de uma linha de atendimento telefónico 24 horas, exclusiva para o doente oncológico. Esta linha, cujo atendimento é feito por enfermeiros de oncologia, tem como objetivo o controlo de sintomas associados à doença ou tratamento antineoplásico e esclarecimento de dúvidas. Com a pandemia, verificou-se um aumento significativo do número de chamadas recebidas, principalmente para esclarecimentos, despiste de sintomas e apoio emocional. $\bigcirc$ doente pode, desta forma, contactar facilmente a sua equipa, controlar sintomas precocemente e ser devidamente encaminhado para avaliação, caso haja essa necessidade. O sistema de triagem utilizado que dá apoio à linha telefónica é uma versão adaptada da "UKONS Triage Toolkit", elaborado pela Sociedade de Enfermagem Oncológica do Reino Unido. ${ }^{8}$ A existência de uma linha de apoio telefónico revelou-se, neste contexto, um acréscimo na segurança e qualidade dos cuidados de enfermagem prestados. 
Os cuidados em ambulatório, pelo seu caráter não urgente, foram uma das áreas mais afetadas com cancelamento de toda a atividade, nomeadamente na consulta externa. Se as teleconsultas eram uma inovação que esteve a ser planeada nos últimos meses, o caráter de urgência desta pandemia veio criar a pressão necessária para que essa ferramenta ficasse disponível. Assim, em maio deu-se o pontapé de partida para recuperar o contacto com os doentes cujas consultas tinham sido canceladas. Posteriormente, e segundo as recomendações dos órgãos de referência, retomou-se a atividade no edifício das consultas, com triagem pela equipa de enfermagem, reforço na limpeza dos espaços, gestão de salas de espera e circuitos independentes. Para além das teleconsultas, a equipa de enfermagem reforçou o contacto (telefónico) com grupos de doentes com doença crónica, nomeadamente hipertensão arterial e diabetes, permitindo uma maior monitorização e identificação de pessoas que eventualmente necessitavam de consulta presencial, mas que, face à contingência, vinham a adiar a observação.

Os Cuidados Domiciliários CUF, a par de todas as outras áreas, também se reajustaram com as novas orientações, tendo sempre em mente que, a partir do momento de declaração de pandemia, a perceção de exposição ao vírus parecia maior. Aqui a disseminação de EPIs por toda a equipa, a redução das horas de contacto na casa dos doentes, a vigilância de sinais e sintomas de doentes foi fundamental. Sendo grande parte da atividade feita por enfermeiros, no pico da pandemia esta equipa seria, por vezes, a única ligação dos doentes com o exterior, dado que em várias situações os familiares se encontravam em isolamento ou até quarentena. Para além disso, promoveram-se as altas precoces, assim como se disponibilizaram serviços no domicílio que, pré-pandemia, implicavam a vinda dos doentes ao hospital. A maior articulação com o serviço de Oncologia ou os cuidados pós-parto, às puérperas e recém-nascidos, foram alguns dos exemplos. Com uma equipa de enfermagem disponível 24 horas/7 dias por semana, a CUF Cuidados Domiciliários teve, no contexto da pandemia, um papel de relevo, assegurando a articulação com as unidades CUF, triando os doentes que necessitavam de ser encaminhados para as unidades de saúde e funcionando de forma multidisciplinar.

Atualmente, a fase de estabilização mantém níveis de alerta elevados, sobretudo porque ainda não existe uma terapêutica eficaz para erradicação do vírus. Já é possível, no entanto, fazer uma reflexão retrospetiva do que foram estes curtos, mas ao mesmo tempo longos, meses. Esta reflexão permite criar consciência e preparação para novas ocorrências. Embora se discuta que a evolução e investigação em saúde nos proteja deste tipo de eventos, a realidade é que, historicamente, estes fenómenos de saúde pública fazem parte das nossas vidas e continua a existir a probabilidade de novas pandemias. É fundamental que os serviços e equipas de saúde estejam preparados.

Esta pandemia criou, ainda assim, novas oportunidades que poderão (e deverão) manter o seu lugar na saúde e nos cuidados de enfermagem. Destacam-se por importância, mas sem que a ordem exposta reflita a sua relevância, algumas dessas conclusões:

- Conhecimento e atualização constante sobre a infeção pelo novo coronavírus e doença COVID-19 e informação aos profissionais e população em geral;

- Implementação massiva das medidas de controlo de infeção, com atenção contínua às PBCl;

- Processos de comunicação fluidos, com mensagens claras, concisas e transparentes;

- Trabalho multidisciplinar, desde as equipas no terreno até aos órgãos de gestão;

- Desenvolvimento de ferramentas para controlo de EPIs;

- Gestão e atenção ao trabalho das equipas, com envolvimento das equipas nos processos de melhoria;

- Empoderamento da capacidade de liderança e resolução de problemas dos profissionais no terreno;

- Aplicabilidade de ferramentas de telehealth e monitorização remota;

- Reforço das equipas de enfermagem e formação específica e/ou especializada dos enfermeiros, para melhorar articulação com outros serviços e equipas, promover o autocuidado e altas precoces, apostar na vigilância e promoção da saúde e prevenção da doença e na humanização dos cuidados.

Em 2020, os cuidados de enfermagem reforçaram o seu papel para um bom funcionamento dos serviços de saúde, ao serem imprescindíveis para uma boa resposta dos mesmos. Este ano demonstrou ser, de facto, o ano da Enfermagem, mas também, e sobretudo, da importância do trabalho em equipa.

\section{RESPONSABILIDADES ÉTICAS}

CONFLITOS DE INTERESSE: Os autores declaram a inexistência de conflitos de interesse na realização do presente trabalho. 
FONTES DE FINANCIAMENTO: Não existiram fontes externas de financiamento para a realização deste artigo.

PROVENIÊNCIA E REVISÃO POR PARES: Não comissionado; revisão externa por pares.

\section{ETHICAL DISCLOSURES}

CONFLICTS OF INTEREST: The authors have no conflicts of interest to declare.

FINANCING SUPPORT: This work has not received any contribution, grant or scholarship.

PROVENANCE AND PEER REVIEW: Not commissioned; externally peer reviewed.

\section{REFERÊNCIAS}

1. World Health Organization. Rolling updates on coronavírus disease (COVID-19). Geneva: WHO; 2020 [accessed 2020 May 22]. Available from: https://www.who.int/emergencies/ diseases/novel-coronavirus-2019/events-as-they-happen.

2. World Health Organization. Modes of transmission of virus causing COVID-19: implications for IPC precaution recommendations. Geneva:WHO; 2020 [accessed 2020 May 22]. Available from: https://www.who.int/news-room/commentaries/detail/modes-of-transmission-of-virus-causing-covid-19-implications-for-ipc-precaution-recommendations.

3. Webster P. Virtual health care in the era of COVID-19. Lancet. 2020; 395: 1180-1. doi: 10.1016/S0140-6736(20)30818-7.

4. Garg M, Wray C. Hospital medicine management in the time of covid-19: Preparing for a sprint and a marathon. J Hosp Med. 2020;15:305-7. doi: 10.12788/jhm.3427.

5. Dale C, Welling L, Clearfield C. How One Seattle Health System Is Managing the Covid-19 Crisis. Boston: Harvard Business Review; 2020 [accessed 2020 May 31]. Available from:doi: 10.12788/jhm.3427.

6. Oncology Nursing Society. ONS Recommendations for Oncology Staff Assignments During the COVID-19 Pandemic [page on the internet]. Pittsburgh: ONS; 2020 [accessed 2020 May 25]. Available from: https://www.ons.org/oncology-staff-assignments-covid-19.

7. Freitas G. COVID-19: Fase de Mitigação: Reconfiguração dos Cuidados de Saúde na Área da Oncologia. Direção Geral da Saúde, Norma 9/2020. Lisboa: DGS; 2020.

8. United Kingdom Oncology Nursing Society. Oncology/Haematology 24 Hour Triage Rapid Assessment and Access Toolkit [publication on the internet]. London: UKONS; 2016 [accessed 2020 May 25]. Available from: https://www.ukons. org/site/assets/files/1134/oncology_haematology_24_hour_ triage.pdf. 